Final Technical Report

January 1, 2009 through December 31, 2009

Under

Award No. FG36-06G086041

Entitled

\title{
Fuel Cell Research at the University of South Carolina
}

\author{
Submitted by \\ Principal Investigator: John W. Van Zee, PhD \\ College of Engineering and Computing \\ University of South Carolina \\ Columbia, SC 29208 \\ Phone 803-777-2285 \\ Fax 803-777-8142 \\ Email: vanzee@engr.sc.edu
}

Submitted to

DOE Contact : David Harris

Grants Management

RSF Department of Energy

15013, Denver West Parkway

Golden, CO 80401

And

Project Officer: Amy Manheim

U.S. Department of Energy

amy.manheim@ee.doe.gov

202-586-1507 
Five projects were conducted in an effort to supplement the efforts of fuel cell research at the University of South Carolina and to contribute to the Technical Plan for Fuel Cells of the Department of Energy. These efforts include significant interaction with the industrial community through DOE funded projects and through the National Science Foundation's Industry/University Cooperative Research Center (NSF-I/UCRC) for Fuel Cells at USC. The allocation of projects described below leveraged all of these sources of funding without overlap and redundancy.

1. "Novel Non-Precious Metal Catalyst For PEMFCs" (Dr. Branko Popov)

2. "Non Carbon Supported Catalysts" (Dr. John Weidner)

3. "Hydrogen Quality" (Dr. Jean St-Pierre)

4. "Gasket Materials: Mechanical and Chemical Stability in PEMFC" (Dr. Y.J. (Bill) Chao)

5. "Mathematical Modeling of PEM Fuel Cells," (Dr. Sirivatch (Vatch) Shimpalee)

\section{Novel Non-Precious Metal Catalyst For PEMFCs}

This continues DOE award DE-FC36-03GO13108 for which funding was delayed by DOE due to budget constraints. The purpose of this project was to develop an understanding of the feasibility and limitations of metal-free catalysts. A summary of the key results are given below. Further details on the technical accomplishments of this project can be found in the reports from award DE-FC36-03GO13108.

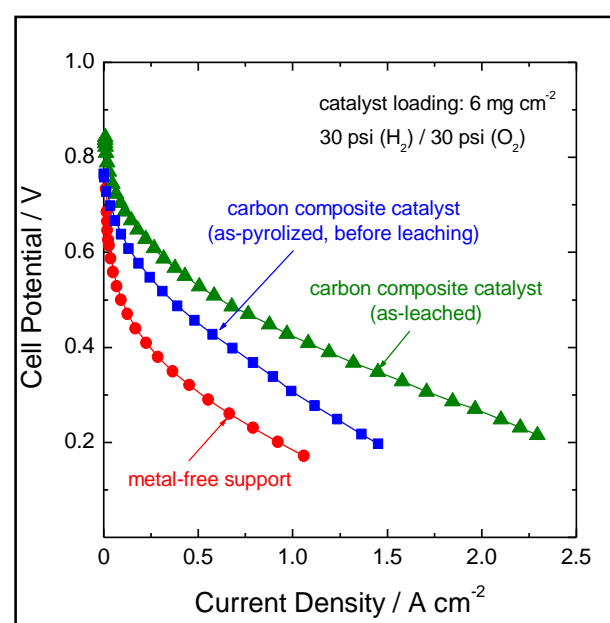

Figure 1. Fuel cell performance of metal-free carbon support, aspyrolyzed carbon composite catalyst and as-leached carbon composite catalyst
A carbon-based metal-free catalyst which serves as support for synthesis of carbon composite catalyst was prepared by activating a porous carbon black with surface functional groups such as oxygen and nitrogen by using a procedure developed at USC [1-4]. Briefly, the asreceived carbon black (e.g., Vulcan XC 72, Ketjen Black EC 300J, Black Pearl 2000, etc.) will be treated in a concentrated $\mathrm{HCl}$ solution to remove metal impurities present on the carbon. Next, the $\mathrm{HCl}$-treated carbon will be refluxed in a concentrated $\mathrm{HNO}_{3}$ solution at $80{ }^{\circ} \mathrm{C}$, in order to introduce oxygen functional groups into the carbon surface. Finally, the oxidized carbon surface will modified with nitrogen functional groups by reacting the carbon with nitrogen-containing organic precursors and thermal/chemical activation processes. The nitrogen modified carbon-based catalysts showed an onset potential of $0.81 \mathrm{~V}(\mathrm{NHE})$ in $0.5 \mathrm{M} \mathrm{H}_{2} \mathrm{SO}_{4}$ solution and the amount of hydrogen peroxide $\left(\mathrm{H}_{2} \mathrm{O}_{2}\right)$ generated was less than $1 \%$ at $0.5 \mathrm{~V}$ under our experimental conditions.

The XPS characterization studies indicated that on the carbon surface, pyridinic and graphitic nitrogen act as catalytic sites for oxygen reduction. Pyridinic nitrogen possesses one lone pair of electrons in addition to the one electron donated to the conjugated $\pi$ bond, facilitates the reductive oxygen adsorption and eliminates $\mathrm{H}_{2} \mathrm{O}_{2}$ formation.

Initial results indicated that onset potential for the oxygen reduction reaction (ORR) on carbon composite catalysts is as high as $0.83 \mathrm{~V}$ vs. standard hydrogen electrode (SHE). The 
catalyst shows only a $70 \mathrm{mV}$ higher overpotential for ORR in comparison to a commercial $19.1 \% \mathrm{Pt} / \mathrm{C}$ catalyst. Rotating ring disk electrode (RRDE) results indicated that the carbon composite catalyst exhibits higher selectivity for oxygen reduction to water when compared with the Pt catalyst. The carbon composite catalyst generated ca. $0.5 \% \mathrm{H}_{2} \mathrm{O}_{2}$ at $0.3 \mathrm{~V}$ vs. SHE compared up to $1.5 \% \mathrm{H}_{2} \mathrm{O}_{2}$ produced in case of the $\mathrm{Pt} / \mathrm{C}$ catalyst. Fuel cell testing employing the synthesized catalyst showed current densities $288 \mathrm{~A} \mathrm{~cm}^{-3}$ at $0.2 \mathrm{~V}$ when the fuel cell was run using back pressures of 30 and 40 psi for $\mathrm{H}_{2}$ and $\mathrm{O}_{2}$, respectively (Fig. 1). Our composite carbon contains only less than $1 \% \mathrm{Fe}$ in the bulk of the graphitic layer which translates to only 0.06 $\mathrm{mg} / \mathrm{cm}^{2}$ of the transition metal. Transition metals are a residue in the bulk of the particle and are used initially only to catalyze nitrogen inclusion in carbon during pyrolysis. The XPS studies indicated that the surface of the activated carbon support (Nitrogen Doped Carbon-Nano Fibers) has only pyridinic and quaternary carbon acting as a catalyst for oxygen reduction. Our catalyst loading represents the amount of pyridinic and quaternary nitrogen which are less than $2 \%$ from a total amount of $2 \mathrm{mg} / \mathrm{cm}^{2}$ of the composite catalyst [1-4].

[1] Vijayadurga Nallathambi, Jong-Won Lee, Swaminatha P. Kumaraguru, Gang Wu, Branko N. Popov, J. Power Sources, 183, 34-42 (2008).

[2] S.Park, Jong-Won Lee, Branko N. Popov, Journal of Power Sources, 177, 457-463 (2008).

[3] X. Li, H.R. Colon-Mercado, G. Wu, J.-W. Lee and B.N. Popov, Electrochem. Solid-State Lett., 10, B201 (2007).

[4] L.Liu, H. Kim, J.-W. Lee and B.N. Popov, J. Electrochem. Soc., 154, A123 (2007).

\section{Non-Carbon Supported Catalysts}

One method of increasing the durability of fuel-cell electrodes is to use inert supports. Unfortunately, replacing carbon with traditional metal-oxide supports is not possible due to their electrical-insulating properties at temperatures below $200^{\circ} \mathrm{C}$. However, metal oxides such as reduced oxidation state titania (e.g. $\mathrm{Ti}_{4} \mathrm{O}_{7}$ and Ebonex) and Niobium-doped $\mathrm{TiO}_{2}$ (e.g., $\mathrm{Nb}_{0.1} \mathrm{Ti}_{0.9} \mathrm{O}_{2}$ ) have shown promise for electrically conductive supports. Titanium oxide based supports may also provide catalytic advantages for the electrochemical oxidation because anatase $\mathrm{TiO}_{2}$ is an active photocatalyst for the destruction of organic compounds. It has been shown that mixtures of $\mathrm{NbO}_{2}$ and $\mathrm{TiO}_{2}$ sintered at $1000^{\circ} \mathrm{C}$ lead to the formation of an electrically conducting material with an electrical conductivity in the range of $0.2-1.5 \mathrm{~S} / \mathrm{cm}$ and a surface area of $\sim 1$

$\mathrm{m}^{2} / \mathrm{g}$. This high temperature synthesis method shows promising results, but it leads to a low surface area material that requires long synthesis times. Since $\mathrm{TiO}_{2}$ undergoes a phase transition from anatase to the less catalytically active rutile near $700^{\circ} \mathrm{C}$, the high temperature synthesis may also reduce some catalytic promotion of methanol oxidation by the support.

We developed a low temperature synthesis route for $\mathrm{Nb}_{0.1} \mathrm{Ti}_{0.9} \mathrm{O}_{2}$ via a surfactant templating method was developed [5]. The supports were characterized using BET, XRD, and TEM techniques. A colloidal method was then used to deposit platinum nanoparticles onto the $\mathrm{Nb}-$ doped titania supports. Their electrochemical activity was measured via cyclic voltammetry by depositing the catalysts onto a disk electrode, and this was compared to the activity of catalysts deposited onto carbon. The catalysts were also evaluated by fabricating them into a membrane electrode assembles (MEAs). 


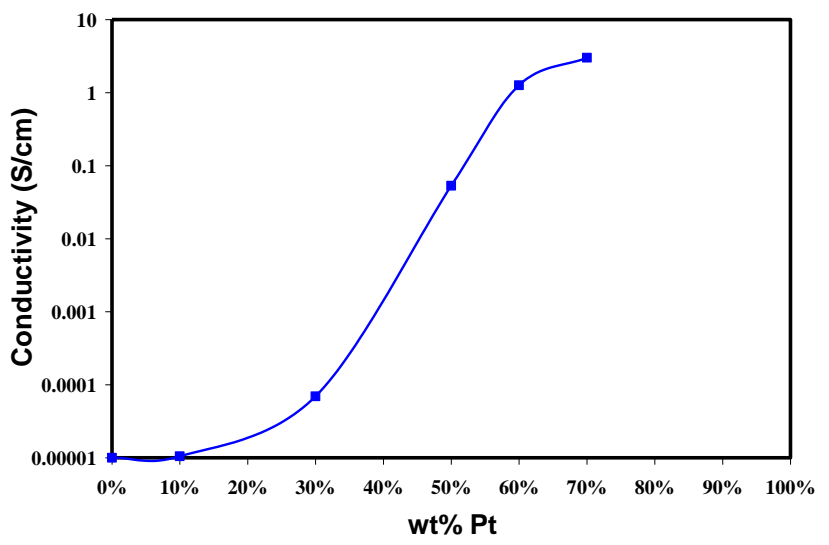

Figure 2: Electronic conductivity of anatase $\mathrm{Nb}$ $\mathrm{TiO}_{2}$ at room temperature as a function of weight percent loading of platinum
The electrodes made with the anatase form of the $\mathrm{Nb}-\mathrm{TiO}_{2}$ supports were as active as those made with carbon, but they are inherently more active. The reason for the activity was that the composite electrode (support + metal catalyst) was conductive as long at the metal loading was high. That is, the electrodes were conductive even though the supports were not. Figure 2 shows the electronic conductivity of the composite electrode as a function of weight percent of platinum loading. At $>50 \mathrm{wt} \%$ Pt (typical in a PEMFC), the electrode is sufficiently conductive to sustain the electrochemical reaction without significant

ohmic voltage loss. The durability of these supports should be excellent since they are already in their oxidized form. The next step is to test the stability of the nanoparticles on the support. The possibility exists that small particles will be more stable on oxides than they are on carbon.

[5] B.L. Garcia, R. Fuentes, and J. W. Weidner, Electrochem. Solid-State Lett., 10, B108-B110 (2007).

\section{Hydrogen Quality}

We performed experiments and developed models that describe performance losses associated with $\mathrm{CO}, \mathrm{NH}_{3}, \mathrm{H}_{2} \mathrm{~S}$ contaminants in the hydrogen fuel feed to laboratory-scale single cells. That work has been focused on reformate fed to a stationary PEMFC and relatively high concentrations of these contaminants, this project will seek to apply that knowledge to the issue of hydrogen fuel quality as it relates to transportation needs. As part of this project USC and Oak Ridge National Laboratory (ORNL) exploreed, in a collaborative effort, the usefulness of a techniques developed at ORNL to measure differences in the extent of contaminates adsorption with a spatially resolved mass spectrometer.

\section{Gasket Materials: Mechanical and Chemical Stability in PEMFC}

We found some materials that give relatively good initial performance and minimal longterm stress relaxation but their raw material cost is higher than that desired by stack and component suppliers. The goals of this project are to obtain a fundamental understanding of the degradation mechanisms of existing gasket and seal materials in a PEMFC environment. We explored the interactions of chemical and mechanical stresses that decrease the long-term durability of both existing and new sealing materials. Both chemical and mechanical degradations are studies were performed to determine the long-term performance of seals and gasket in PEM fuel cells (PEMFC) environment.

Several seal materials supplied by our industrial partners, e.g. liquid silicone elastomer (DLS), Fluorosilicone rubber (DFS), copolymeric resin (DC), Ethylene Propylene Diene M-class rubber (EPDM), and Fluoroelastomer (FKM), have been studied. A 63 week long testing program using this group of materials was completed recently. Seal materials are aged in simulated regular and accelerated fuel cell solutions. Samples are taken out of the test ovens on a weekly basis or so and their chemical and mechanical stabilities are assessed by various 
methods. The results are being summarized and technical papers are being prepared. We are developing a stress relaxation model for the materials under study. The objective is to be able to predict the sealing force at any moment during the life time of a PEMFC. The model will use compression stress relaxation test data, Arrhenius equation, and WLF time-temperature shift for long term sealing force prediction as well as estimation of the life of the seals in PEMFC. From our work, in addition to technical publications in journals, we anticipate to have a stand-alone software that can be used by fuel cell companies to predict the sealing force during service and the life of the seals/gaskets in their PEMFC products.

\section{Mathematical Modeling of PEM Fuel Cells}

Water transport inside the gas diffusion layer (GDL) plays an important role in the performance of fuel cells. Particularly in the cathode, the GDL must permit reactant gases to be transported from the flow channel to be distributed in the catalyst layer and provide the pathway for the product water (gas and liquid) to be removed from the catalyst layer. However, the water transport in the GDL depends on the characteristics of the porous media used which are still not completely understood.

The objective of this project is to describe polymer electrolyte membrane fuel cell (PEMFC) behavior resulting from changes in the fundamental properties of GDLs. This objective is being accomplished by measuring the GDL properties, including micro and macro porous layers, fuel cell performance under a variety of operating conditions, and by developing a mathematical model. The GDL characterization includes pore size distribution (PSD) using techniques such as mercury intrusion porosimetry and the method of standard porosimetry. The use of multiple working fluids to access hydrophilic and hydrophobic pores as well as limitations associated with structural changes of the GDLs during the tests has been addressed [6,7]. Also, measurement of the MacMullin number has been performed which show that only carbon-cloth GDLs follow the Bruggeman equation and that carbon-paper GDM has a different relationship with porosity. Scanning electron microscopic (SEM) images were used to illustrate differences in structures. Finally, characteristics of the GDL are being incorporated into a two-phase 1D + 1D model in order to describe water phase distribution.

The long-term goal is to provide a consistent, comprehensive database of these properties and the respective GDL performance under a wide range of operating conditions. Model predictions will bring the engineering fundamentals which will help to understand the experimental data. It is expected that this database and model predictions can be used to facilitate the development of optimum gas diffusion media (GDM) for PEMFCs at minimal manufacturing cost.

[6] M. J. Martínez, S. Shimpalee, and J. W. Van Zee, Measurement of MacMullin Numbers for PEMFC Gas-Diffusion Media, J. Electrochem. Soc., 156 (1), B80-B85, 2009.

[7] M. J. Martínez, S. Shimpalee, J. W. Van Zee, and A. V. Sakars, Assessing Methods and Data for Pore-Size Distribution of PEMFC Gas-Diffusion Media, J. Electrochem. Soc., 156 (5), B558-B564, 2009. 